Hydrological Research Letters, 4, 55-59 (2010)

Published online in J-STAGE (www.jstage.jst.go.jp/browse/HRL). DOI: 10.3178/HRL.4.55

\title{
Suspended sediment transport in a river basin estimated by chemical composition analysis
}

\author{
Tetsuya Ishida ${ }^{1}$, Keisuke Nakayama ${ }^{2}$, Tomonari Okada ${ }^{3}$, Yasuyuki Maruya ${ }^{4}$, \\ Kiyofumi Onishi ${ }^{4}$ and Mio Omori ${ }^{5}$ \\ ${ }^{I}$ Shinanogawa River Office, Hokuriku Regional Department Bureau, Ministry of Land, Infrastructure, Transport \\ and Tourism, Niigata, Japan \\ ${ }^{2}$ Department of Civil and Environmental Engineering, Kitami Institute of Technology, Hokkaido, Japan \\ ${ }^{3}$ Marine Environment Division, National Institute for Land and Infrastructure Management, Kanagawa, Japan \\ ${ }^{4}$ Graduate School of Civil Engineering, Kitami Institute of Technology, Hokkaido, Japan \\ ${ }_{5}^{5}$ Abashiri Development and Construction Department, Hokkaido Regional Development Bureau, Ministry of Land, \\ Infrastructure, Transport and Tourism, Hokkaido, Japan
}

\begin{abstract}
:
Production and transportation of suspended sediment was investigated by sampling surface soils in 18 domains over an entire river basin. Particle size distributions alone suggested that all domains were a source of suspended sediment. Chemical composition analysis however showed that the transport rate of suspended sediment was more closely related to the type of surface soil than to land use. A method was developed which enables estimation of the relative suspended sediment transport rates from each domain of a river basin to its downstream end. The model's validity was verified through good agreement with field sampling results.
\end{abstract}

KEYWORDS sediment transport; chemical composition; particle diameter distribution; GIS

\section{INTRODUCTION}

High suspended sediment (SS) inputs from rivers can have significant impacts on the ecology of nearshore systems, and it is thus important to clarify the mechanisms involved in SS production and transport. There are many examples of the impact of high turbidity from rivers on coastal ecosystems, such as coral reefs in Okinawa (Osawa et al., 2005a; Osawa et al., 2005b) and coastal areas of the Okhotsk Sea due to the influence of the Tokoro River, which is the longest river in the Okhotsk area of Hokkaido. In June of 2007, very high turbidity water in the Tokoro River was pumped into the domestic water supply system, which resulted in the cessation of water supply for up to four days. The very high concentration of SS in the small river basins of the Tokoro River was considered the main factor causing the failure of the water supply system. Therefore, it is important that the production of SS from small river basins is understood, as well as the mechanisms of transport.

High SS in rivers has been shown to result from dilapidated land and fields and from logging roads; the flux of SS from river basins is thus related to land use and surface

Corresponding to: Tetsuya Ishida, Shinanogawa River Office, Hokuriku Regional Department Bureau, Ministry of Land, Infrastructure, Transport and Tourism, 1-5-30 Shinano, Nagaoka, Niigata 940-0098, Japan. E-mail: ishida-t84qa@hrr.mlit.go.jp (c)2010, Japan Society of Hydrology and Water Resources. soil type (Sidle et al., 2007). Radionuclide analysis has been used to evaluate the production of SS in river basins where surface erosion is the dominant process (Wallbrink and Murray, 1993; Walling et al., 2003; Uchida et al., 2009; Mizugaki et al., 2008). For instance, to clarify the reason for increased sedimentation in the Sengguruh Reservoir, Uchida et al. (2009) examined radionuclide $\mathrm{Pb}-210 \mathrm{ex}$ in the Brantas river basin, demonstrating the potential use of radionuclides for the long-term evaluation of surface soil erosion (Uchida et al., 2009). Mizugaki et al. (2008) further demonstrated the potential of radionuclides in the evaluation of nutrient cycles, which play a significant role in ecological systems.

Regarding ecological systems, stable isotope analysis has been used to evaluate mutual interactions between the coastal zone and inland areas by using $\mathrm{N}$ and $\mathrm{C}$. Analysis of the stable isotope ratios of certain elements can be used to determine whether a sample is predominately oceanic or terrestrial in origin, providing insights into nutrient cycling between coastal and terrestrial systems. For instance, Kline et al. (1990) used isotope analysis to show that oceanic nutrients are transported into the upstream areas of the Sashin River by Pacific salmon.

Radionuclide and stable isotope analysis can indicate the source of SS in a river basin, but cannot indicate the relative amounts of SS transported from each individual catchment area within a basin. Due to the limited number of radionuclide tracers available, the SS contribution from each individual catchment cannot be evaluated. Therefore, in this study we make an attempt to apply chemical composition analysis to examine SS dynamics. Chemical composition analysis, which can measure the chemical composition of up to 22 elements, has previously been used in geology, petrology and mineralogy (Miki et al., 2003; Shinjo et al., 2002). In previous studies, chemical composition has not been used to evaluate the transportation rate of mass in a river basin, instead only being used to understand the geophysical dynamics.

Therefore, in this study, to understand the physical conditions near the soil surface, a river basin with length of approximately $9.7 \mathrm{~km}$ was divided into 18 domains, and soil sampling was conducted in each domain and at the

Received 15 February, 2010 Accepted 18 May, 2010 
downstream end of the river. We propose a method which can enable estimation of the SS transportation rate from each domain to the downstream end of the river. Estimation of SS transportation rate is useful for input into distributed hydrological models which can provide detailed understanding of mass transport based on physics (Dutta and Nakayama, 2009).

\section{METHOD}

The Oromushi River, a branch of the Tokoro River, has a length, basin area and mean slope of $9.7 \mathrm{~km}, 29.3 \mathrm{~km}^{2}$ and $1 / 43$, respectively. The river mouth is located at $4343^{\prime} \mathrm{N}$, 143 47'E (Figure S1 in Supplement). The main land uses in the catchment are forest $(80.7 \%)$ and fields $(15.7 \%)$, with the dominant surface soil types being Terrestrial Regosols (59.6\%), and Andosols (32.6\%) (Figures 1 and 2). Land use and surface soil type are considered the main factors controlling the production and transportation rate of SS in a river basin. We thus carried out soil sampling in 18 domains of the Oromushi River basin, taking into account land use and surface soil type based on Geographic Information System (GIS) data (Figures 1 and 2). In each sampling domain of the Oromushi River basin, and at one downstream end of the river, three samples $15 \mathrm{~cm} \times 15 \mathrm{~cm} \times 5 \mathrm{~cm}$ (horizontal square area $\times$ depth) were taken from the soil surface (Figure 3).

Firstly, to understand SS production in each sampling domain the particle size distribution was investigated using a Laser Scattering Particle Distribution Analyzer (LA-950, HORIBA Ltd.). Since the largest particles in the Oromushi River basin are less than $2 \mathrm{~mm}$, the target region for chemical composition analysis was chosen to be $0.1 \mu \mathrm{m}$ to $2 \mathrm{~mm}$.

To clarify the characteristics of SS in the Oromushi River basin and at the downstream end of the river, chemical composition was measured for particles with diameter less than $63 \mu \mathrm{m}$ using a X-ray Fluorescence Analyzer after being sieved with water (Supermini, Rigaku) (Kansai, 2008).

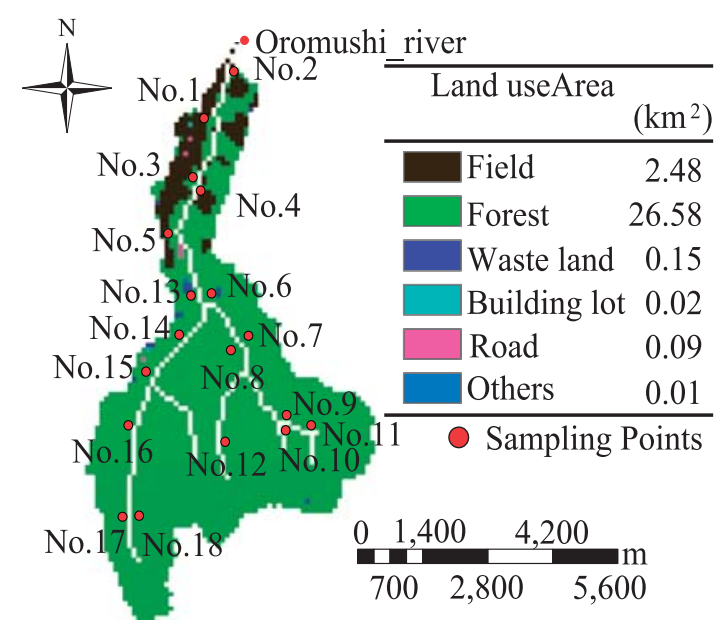

Figure 1. Land use and sampling points in the Oromushi River basin.

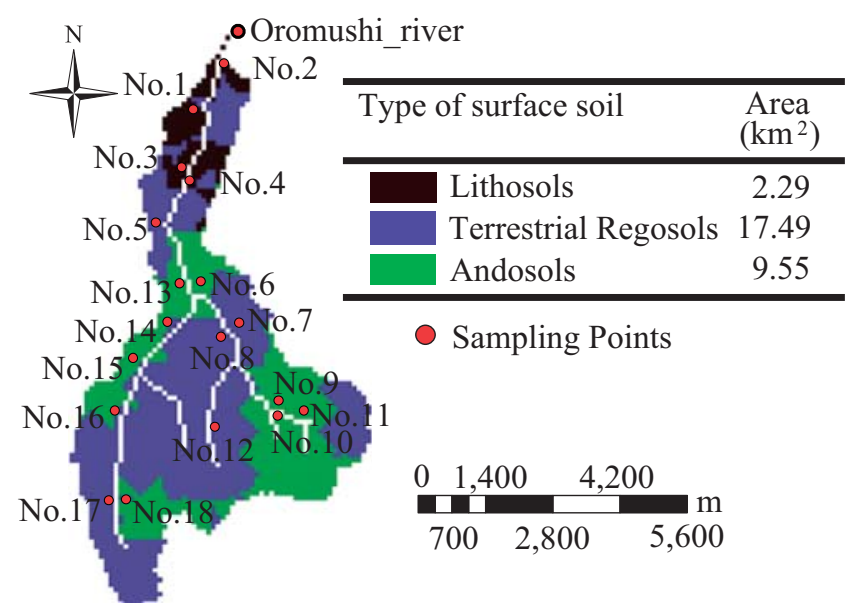

Figure 2. Types of surface soil and sampling points in the Oromushi River basin.

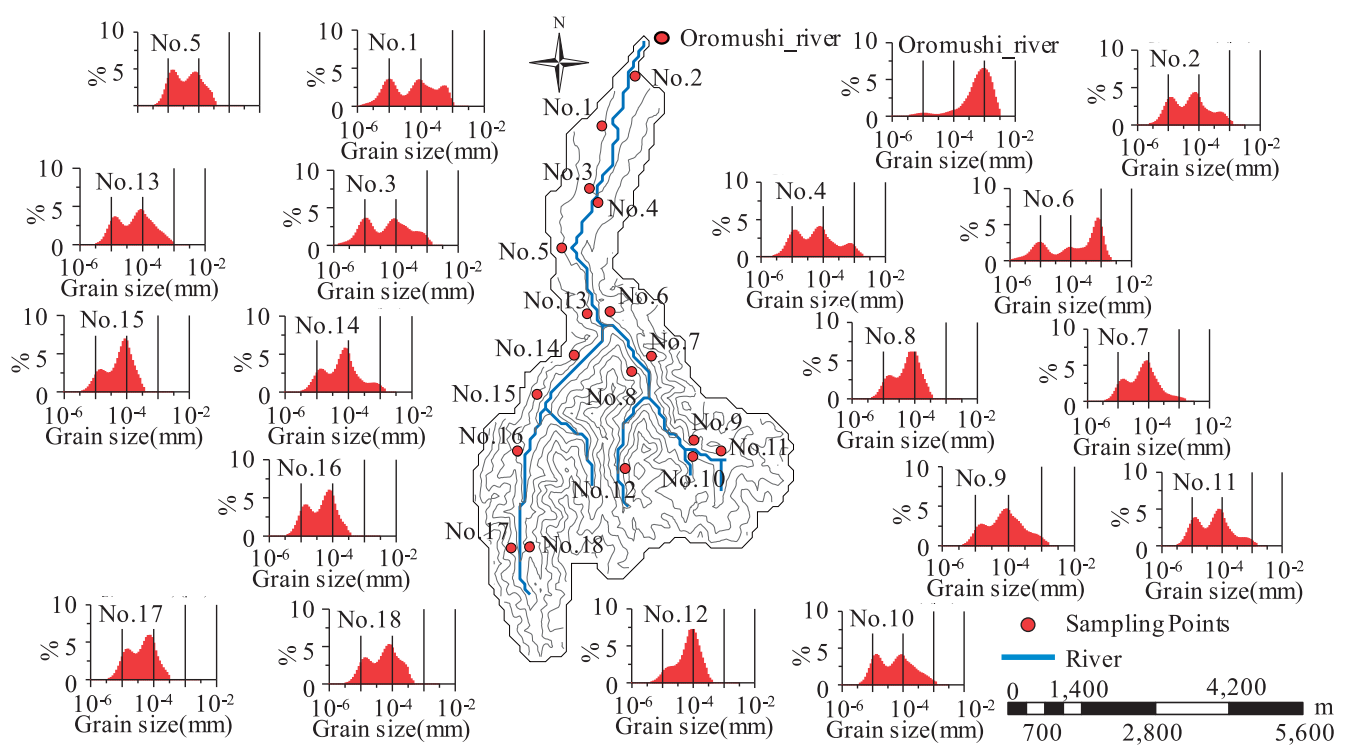

Figure 3. Particle size distribution (\%) at each sampling point. 
Sediment sampling at the downstream end of the river was conducted from the stream bed, which may represent accumulated soil from further upstream. After sieving through a $63 \mu \mathrm{m}$ sieve with distilled water, the soil was dried for $24 \mathrm{hrs}$ at 110 Celsius degrees. The dried soil was ground using an alumina mortar and pressed to make a circular shaped sample with diameter of $3 \mathrm{~cm}$ and $1 \mathrm{~mm}$ thickness. The medal-type sample was used to measure chemical decomposition using X-ray Fluorescence Analyzer. $\mathrm{Na}_{2} \mathrm{O}, \mathrm{MgO}, \mathrm{Al}_{2} \mathrm{O}_{3}, \mathrm{SiO}_{2}, \mathrm{P}_{2} \mathrm{O}_{5}, \mathrm{SO}_{3}, \mathrm{Cl}, \mathrm{K}_{2} \mathrm{O}, \mathrm{CaO}, \mathrm{TiO}_{2}$, $\mathrm{Cr}_{2} \mathrm{O}_{3}, \mathrm{MnO}, \mathrm{Fe}_{2} \mathrm{O}_{3}, \mathrm{Co}_{2} \mathrm{O}_{3}, \mathrm{NiO}, \mathrm{CuO}, \mathrm{ZnO}, \mathrm{Rb}_{2} \mathrm{O}, \mathrm{SrO}$, $\mathrm{BaO}$, and $\mathrm{Y}_{2} \mathrm{O}_{3}$ were measured (Goto and Tatsumi, 1991). $\mathrm{C}$ was measured separately using an ignition loss test.

When the chemical composition was similar between a river basin sampling point and the downstream end of the river, the sampling point was considered to be a significant source of SS for the downstream end. Therefore, we made an attempt to develop a new method for evaluating transportation rate by computing the correlation between the chemical composition of each sampling point in the river basin and the downstream end.

The error of similarity was computed by Equation (1). The lower the value of Err ${ }_{i}$, the higher the similarity in chemical composition. We thus call the value obtained from Equation (1) 'error of similarity'. Carbon was not included in the analysis so as to exclude the influence of particulate organic matter. Chemical composition values less than 0.01 $\%$ were also excluded from the analysis.

$$
E r r_{i}=\left(\mathrm{Na}_{2} \mathrm{O}_{\text {river }}-\mathrm{Na}_{2} \mathrm{O}_{i}\right)^{2}+\left(\mathrm{MgO}_{\text {river }}-\mathrm{MgO}_{i}\right)^{2}+. .
$$

where river indicates the value at the downstream end, $i$ is the station number of the river basin, and $\operatorname{Err}_{i}$ is the summation of the squared value of chemical composition $\left(\%{ }^{2}\right)$.

\section{RESULTS AND DISCUSSION}

No significant relationships were found between land use, surface soil type and particle size distribution (Figures 1, 2, and 3). At all sampling points, particle size distribution showed two peaks in the $10-15 \mu \mathrm{m}$ and $80-100 \mu \mathrm{m}$ ranges, with a split at around $63 \mu \mathrm{m}$, which is the size generally used to distinguish between sand and clay. The peak in fine sediment (diameter less than $63 \mu \mathrm{m}$ ) was confirmed in all domains.

Chemical composition analysis showed that sediments at all sampling points were predominately composed of $\mathrm{Al}_{2} \mathrm{O}_{3}, \mathrm{SiO}_{2}$ and $\mathrm{Fe}_{2} \mathrm{O}_{3}$, with these elements contributing from 85 to $93 \%$ of the total composition (Figure 4). Although the predominant elements were the same among the 18 domains, significant differences in the chemical composition were found in the pattern of chemical composition. We thus applied multiple linear regression analysis using the data from the 18 sampling points and the downstream end in order to estimate the contribution of SS from each sampling point to that of the downstream end. However, multiple linear regression analysis was not valid. Therefore, the summation of the squared value of chemical composition was computed using equation (1). The errors of similarity for Nos. 1 to $4,6,9$ to 11,13 and 17 were relatively lower, which indicates that the transportation rate from these domains may be higher than from the other domains (Figure 5).

Based on the diameter distribution of particles alone, it was conceivable that the whole river basin was a source of SS (Figure 3). Chemical composition analysis however allowed us to evaluate the role of transportation rate from each domain of the river basin on the production of SS and thereby identify the domains most influential in SS supply to the downstream end of the river (Figure 5). We thus propose a method for evaluating SS transport rates from each domain of a river basin to the downstream end by using Equation (2). In Equation (2), the size of each domain is ignored because each domain is of a similar size (average $1.6 \mathrm{~km}^{2}$ with standard deviation of $0.9 \mathrm{~km}^{2}$ ). However, it may be necessary to include the effect of size in future studies in order to evaluate SS transport rates more accurately, especially where domain sizes vary widely.

$$
\operatorname{Tr}_{i}=\frac{1 / E r r_{i}}{E r r_{T}}
$$
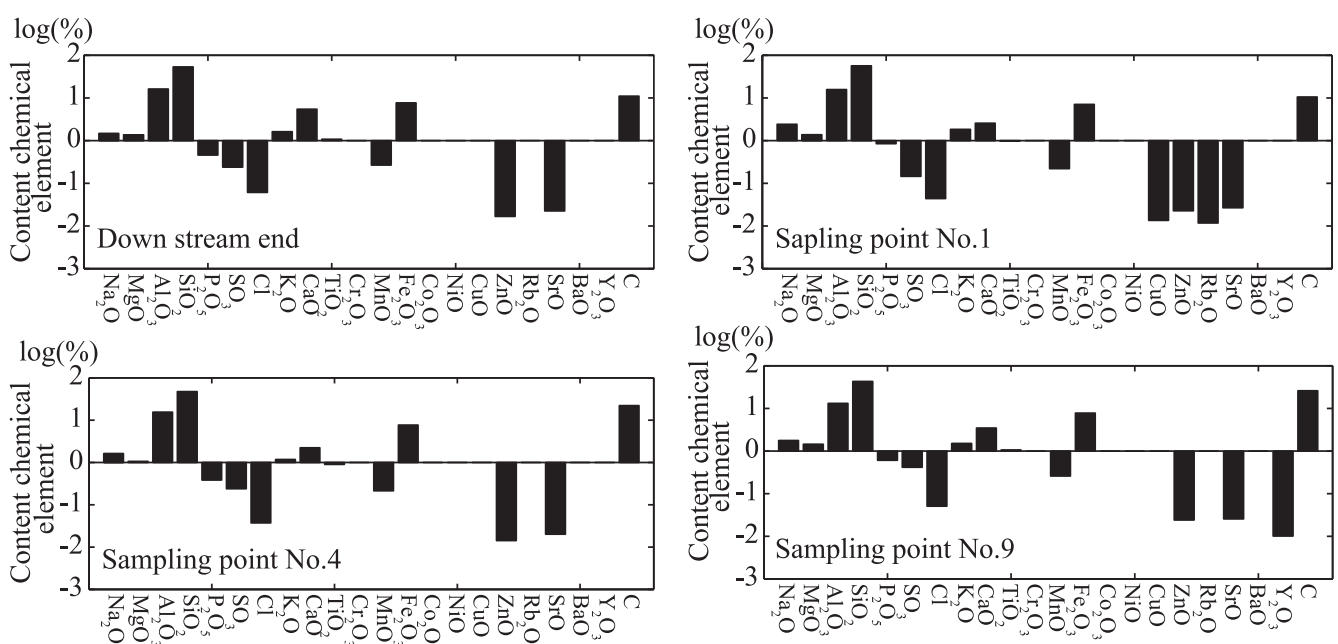

Figure 4. Chemical composition (\%) at the downstream end, Nos. 4, 1 and 9 (From the top left, the top right to the bottom right). 


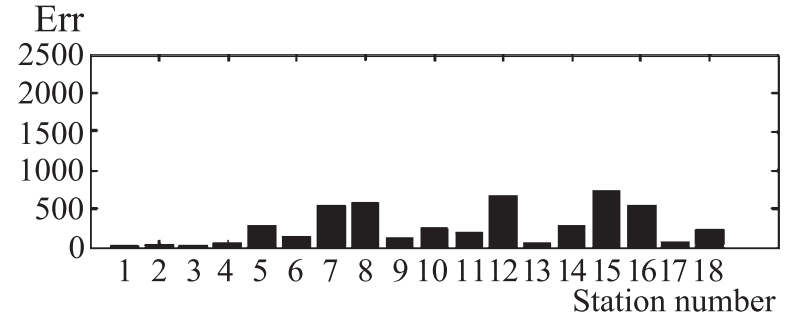

Figure 5. Error of similarity computed using Equation (1). Organic matter excluded.

$$
\operatorname{Err}_{T}=\sum_{i=1}^{N} \frac{1}{E r r_{i}}
$$

where $N$ is the total number of stations and $T r_{i}$ is the transportation rate from each domain of the river basin to the downstream end.

To verify the method developed, chemical composition at the downstream end was reproduced by using the estimated transportation rate shown as Equation (4).

$$
\begin{aligned}
& X_{\text {river_E }}=\sum_{i=1}^{N} \operatorname{Tr}_{i} X_{i} \\
& \text { Err }_{\text {chemical }}=\sqrt{\sum_{X=\mathrm{Na}_{2}, \mathrm{MgO}, \ldots, \mathrm{Y}_{2} \mathrm{O} 3}\left(X_{\text {iver }}-X_{\text {river_E }}\right)^{2}}
\end{aligned}
$$

where $X$ represents $\mathrm{Na}_{2} \mathrm{O}, \mathrm{MgO}, \mathrm{Al}_{2} \mathrm{O}_{3}, \mathrm{SiO}_{2}, \mathrm{P}_{2} \mathrm{O}_{5}, \mathrm{SO}_{3}$, $\mathrm{Cl}, \mathrm{K}_{2} \mathrm{O}, \mathrm{CaO}, \mathrm{TiO}_{2}, \mathrm{Cr}_{2} \mathrm{O}_{3}, \mathrm{MnO}, \mathrm{Fe}_{2} \mathrm{O}_{3}, \mathrm{Co}_{2} \mathrm{O}_{3}, \mathrm{NiO}$, $\mathrm{CuO}, \mathrm{ZnO}, \mathrm{Rb}_{2} \mathrm{O}, \mathrm{SrO}, \mathrm{BaO}$, and $\mathrm{Y}_{2} \mathrm{O}_{3}(\%)$, river $E$ is the reproduced chemical composition at the downstream end (\%), and $E r r_{\text {chemical }}$ is the sum of errors for all chemicals (\%).

It was found from the comparisons that the reproduced and measured chemical composition at the downstream end agreed very well (Figures 6 and 7). To confirm the validity of the proposed method, we computed the chemical composition by giving a constant transportation rate, $T r$, $1 / 18$, which implies SS is transported from each domain to the downstream end equally. The error compared with the measured chemical composition was computed by using Equation (5) for both the estimated and constant transportation rate cases, which were 1.77 and 2.90, respectively. The estimated transportation rate of SS from Equation (2) was thus found to reduce the error in the evaluation of the chemical composition at the downstream end to $60 \%$ when compared to the constant transportation rate.

Spatial patterns of SS transportation rate did not seem to be strongly related to land use (Figures 1 and 6). However the relationship between the spatial patterns in surface soil type and SS transport rate was slightly significant (Figures 2 and 6), with higher transportation rates in the domains dominated by Lithosols and Andosols. The transportation rate was particularly high in the Lithosols domains, which cover the downstream domains of the Oromushi River. These results suggest the same possibility for the evaluation of sediment transportation rate using radionuclide shown in Uchida et al. (2009) and Mizugaki et al. (2008). Also,

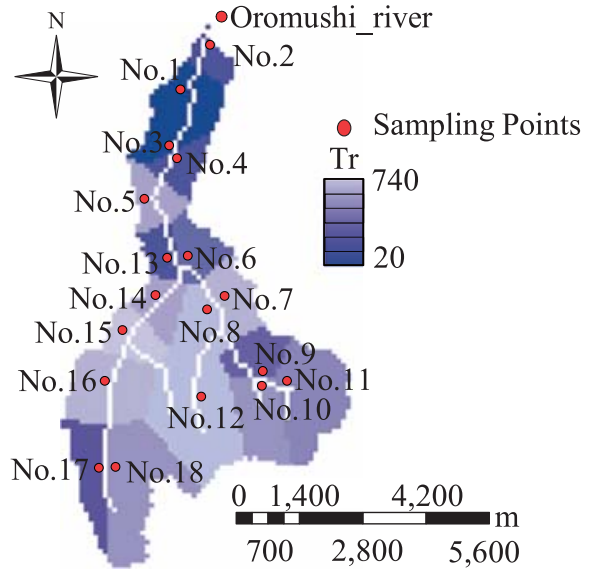

Figure 6. Transportation rate of SS in the Oromushi River basin.

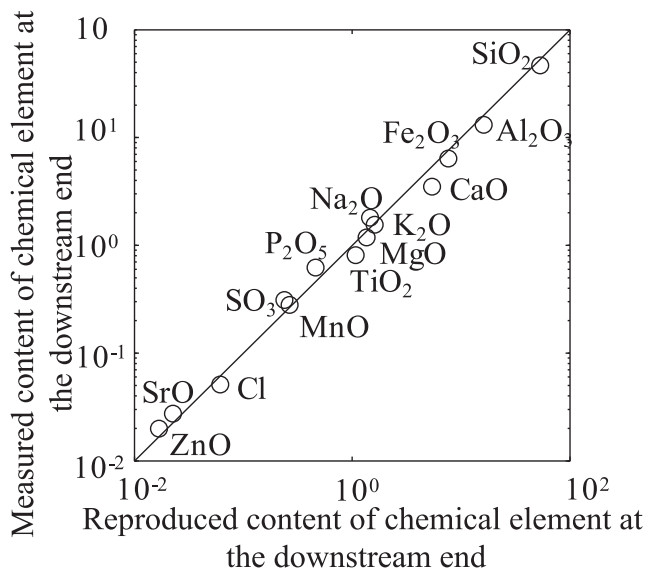

Figure 7. Comparison between reproduced and measured chemical composition (\%) at the downstream end.

Katsuyama et al. (2008) demonstrated that runoff characteristics are likely to be controlled by the soil type. Therefore, it is likely that SS is predominately produced in the downstream domains of the river, and that Lithosols and Andosols are the main source.

\section{CONCLUSIONS}

To clarify the formation of high turbidity water, the production and transport of SS was investigated by examining particle size distributions and chemical composition of surface soils at 18 points over the whole river basin. The findings suggest:

1) Two dominant peaks are found in the particle diameter distribution at $10-15 \mu \mathrm{m}$ and $80-100 \mu \mathrm{m}$ across the whole basin, suggesting that SS is likely to be sourced from the whole river basin. Correspondingly, chemical composition of all soils was dominated by $\mathrm{Al}_{2} \mathrm{O}_{3}, \mathrm{SiO}_{2}$, $\mathrm{Fe}_{2} \mathrm{O}_{3}$ and $\mathrm{C}$.

2) The error of similarity between chemical composition at each sampling point and the downstream end was found to be lower for several domains: Nos. 1 to 4, 6, 
9 to 11,13 and 17 . This suggests that these domains make a higher contribution to SS production.

3) The method proposed for estimating SS transportation rate revealed that surface soil type is slightly related to the transportation rate. Also, the higher transport rate domains appear to correspond to domains dominated by Lithosols and Andosols.

The study demonstrates the potential to estimate SS transportation rate by using chemical composition analysis. This anaylsis may be applied to verify the parameters regarding SS production and water quality in runoff models, such as the distributed hydrological model.

\section{ACKNOWLEDGMENTS}

We wish to thank Mr. Arasawa and Mr. Takemura for performing the field experiments. This work has been supported by the Japan Society for the Promotion of Science and Kurita Water and Environment Foundation.

\section{SUPPLEMENTS}

Figure S1. Tokoro river basin $\left(1,930 \mathrm{~km}^{2}\right)$ and Oromushi river basin $\left(29.3 \mathrm{~km}^{2}\right)$

\section{REFERENCES}

Alam MJ, Dutta D, Nakayama K. 2009. Modelling Nutrient Dynamics and Transport Process in River Basin: A Case Study-Saru River, Japan, the 7th Eco-Hydraulics, Topic 13. Solute and Nutrient Transport and Exchange 30: 1-10.

Dutta D, Nakayama K. 2009. Effects of Spatial Grid Resolution on River Flow and Surface Inundation Simulation by Physically Based Distributed Modeling Approach, Hydrological Processes 23(4): 534-545. doi:10.1002/hyp.7183.

Goto A, Tatsumi Y. 1991. Rock Sample Quantitative Analysis (I) Using X-ray Fluorescent Analysis Device. Rigaku-Denki Journal 22: 28-60 (in Japanese).

Kansai K. 2008. Rock Analysis Using X-ray Fluorescent Analysis Method. Rigaku Journal 39(1): 31-34 (in Japanese).

Katsuyama M, Fukushima K, Tokuchi N. 2008. Comparison of Rainfall-Runoff Characteristics in Forested Catchments
Underlain y Granitic and Sedimentary Rock with Various Forest Age. Hydrological Research Letters 2: 14-17. doi: 10.3178/HRL.2.14

Kline TC, Goering JJ, Mathisen OA, Poe PH, Parker PL. 1990. Recycling of elements transported upstream by runs of Pacific salmon: I. delta-15 N and delta-13 C evidence in Sashin Creek, southeastern Alaska. Canadian Journal of Fisheries and Aquatic Sciences 47: 136-144.

Miki D, Uto K, Sudo M, Ishiharam K. 2003. Correlation of Levas on Drilled Cores from the Sakurajima Volcano, Inferred from Paleomagnetic and Chemical Features. Annuals of Disaster Prevention Research Institute, Kyoto University 46(B): 835840 (in Japanese).

Mizugaki S, Onda Y, Fkuyama T, Koga S, Asai H, Hiramatsu S. 2008. Estimation of suspended sediment sources using Cs137 and $\mathrm{Pb}-210$ in unmanaged Japanese cypress plantation watersheds in southern Japan. Hydrological Processes 22(23): 4519-4531. doi: 10.1002/hyp.7053.

Osawa K, Ikeda S, Yamaguchi S. 2005a. Field observation and WEPP application for sediment yield in an agricultural watershed. River, Coastal and Estuarine Morphodynamics: 1137-1146.

Osawa K, Yamaguchi S, Ikeda S, Takamuku K. 2005b. Field observation of sediment runoff reduction methods on farmland. Journal of hydroscience and Hydraulic Engineering 49: 1099-1104.

Sidle RC, Hirano T, Gomi T, Terajima T. 2007. Hortonian overland flow from Japanese forest plantations - an aberration, the real thing, or something in between? Hydrological Processes 21(23): 3237-3247. doi:10.1002/hyp.6876.

Shinjo H, Orihashi Y, Sumi T, Nakai S. 2002. Bulk rock chemistry of the Muro pyroclastic flow deposit: a clue to its source region. Japanese Magazine of Mineralogical and Petrological Sciences 31: 307-317 (in Japanese)

Uchida T, Takahashi F, Onda Y, Sisingghi D, Kato H, Noro T, Osanai N. 2009. Estimating soil erosion rate and sediment sources using radionuclide $\mathrm{Pb}-210$ ex upper brantas river basin in Indonesia. Journal of Japan Society of Hydrology and Water Resources 22(3): 188-197.

Wallbrink PJ, Murray AS. 1993. Use of fallout radionuclides as indicators of erosion processes. Hydrological Processes 7(3): 297-304. doi: 10.1002/hyp.3360070307.

Walling DE, Collins AL, Sichingabula HM. 2003. Using unsupported lead-210 measurements to investigate soil erosion and sediment delivery in a small Zambian catchment. Geomorphology 52(3-4): 193-213. doi: 10.1016/S0169555X(02)00244-1. 